\title{
A retrospective analysis of delays in the diagnosis of lung cancer and associated costs
}

This article was published in the following Dove Press journal:

ClinicoEconomics and Outcomes Research

12 May 2017

Number of times this article has been viewed

\author{
Thomas R Gildea' \\ Stacey DaCosta Byfield ${ }^{2}$ \\ D Kyle Hogarth ${ }^{3}$ \\ David S Wilson ${ }^{4}$ \\ Curtis C Quinn ${ }^{5}$ \\ 'Department of Pulmonary, Allergy, \\ and Critical Care Medicine and \\ Transplant Center, Cleveland Clinic, \\ Cleveland, $\mathrm{OH},{ }^{2} \mathrm{Health}$ Economics \\ and Outcomes Research, Optum, \\ Eden Prairie, MN, ${ }^{3}$ Department of \\ Medicine, Section of Pulmonary and \\ Critical Care, University of Chicago \\ Medical Center, Chicago, IL, ${ }^{4}$ The Lung \\ Institute, Columbus Regional Hospital, \\ Columbus, IN, ${ }^{5}$ Cardiothoracic \\ Surgery/Thoracic Surgery, \\ Cardiothoracic Surgery of Charleston, \\ Roper St. Francis Physician Partners \\ Group, Charleston, SC, USA
}

Correspondence: Thomas R Gildea Cleveland Clinic, 9500 Euclid Avenue, Mail Code M2-I4I, Cleveland, $\mathrm{OH}$ 44195, USA

Tel +12164446490

Fax + I 2164450474

Email gildeat@ccf.org
Purpose: Diagnosis of lung cancer at advanced stages can result in missed treatment opportunities, worse outcomes, and higher health care costs. This study evaluated the wait time to diagnose non-small-cell lung cancer (NSCLC) and the cost of diagnosis and treatment based on the stage at diagnosis.

Patients and methods: Adult patients diagnosed with NSCLC between January 2007 and September 2011 were identified from a proprietary oncology registry and linked to health insurance claims from a large US health insurance company. Continuous enrollment in the health plan was required for at least 12 months prediagnosis (baseline) and at least 3 months postdiagnosis (follow-up). Use of diagnostic tests and time to diagnosis were examined. The rates of health care utilization and per-patient per-month (PPPM) health care costs were calculated.

Results: A total of 1,210 patients with NSCLC were included in the analysis. Most patients (93.6\%) had evidence of diagnostic tests beginning 5 to 6 months prior to diagnosis, and most were diagnosed at an advanced stage (23\% Stage IIIb and $46 \%$ Stage IV). The PPPM total health care costs in USD pre- and postdiagnosis were $\$ 2,407 \pm \$ 3,364$ (mean \pm standard deviation) and $\$ 16,577 \pm \$ 33,550$, respectively. PPPM total health care costs and utilization after lung cancer diagnosis were significantly higher among patients diagnosed at Stage IV disease and lowest among patients diagnosed at Stage I disease (\$7,239 Stage I, \$9,484 Stage II, \$11,193 Stage IIIa, \$17,415 Stage IIIb, and \$21,441 Stage IV).

Conclusion: This study showed that most patients experienced long periods of delay between their first diagnostic test for lung cancer and a definitive diagnosis, and the majority were diagnosed at advanced stages of disease. Costs associated with the management of lung cancer increased substantially with higher stages at diagnosis. Procedures that diagnose lung cancer at earlier stages may allow for less resource use and costs among patients with lung cancer.

Keywords: biopsy (lung), cost, health care utilization, pulmonary nodule, staging

\section{Plain language summary}

Lung cancer is usually diagnosed at a late stage because it often has no symptoms until it has spread. Late diagnosis lowers the chance of survival and increases health care costs. However, little is known about the cost of diagnosing lung cancer compared with treating it and how these costs are affected by the stage at diagnosis. This study used information from an insurance claims database and found that $>90 \%$ of patients had a long delay (5-6 months) before receiving a definite diagnosis of lung cancer. The average total health care costs in USD related to lung cancer for a single patient were $\sim \$ 2,400$ /month to get the diagnosis (for imaging, biopsies, and other tests) and $\sim \$ 16,000 /$ month after the diagnosis (for doctor, hospital, and pharmacy costs to treat the disease). Although the cost of diagnosing lung cancer was similar whether a patient had early- 
stage or late-stage disease, the cost of treating it was much higher for patients with Stage IV lung cancer (\$21,000/month) compared with patients with Stage I lung cancer (\$7,000/month). These results are important to patients, doctors, and insurance companies because they highlight the value of diagnosing lung cancer early to increase the chances of survival and reduce health care costs.

\section{Introduction}

Although diagnostic and therapeutic strategies for lung cancer have improved in recent years, it remains the leading cause of cancer death in the US. ${ }^{1}$ Patients often present to the treating physician with an advanced stage of the disease, which may partially account for the high mortality rate. ${ }^{1-3}$ Non-small-cell lung cancer (NSCLC) accounts for $\sim 85 \%$ of all lung cancers ${ }^{4}$ and, as with overall lung cancer diagnoses, a reported $65 \%$ of NSCLC cases are diagnosed at late stages of disease. ${ }^{5}$

Total direct health care expenditures associated with lung cancer are substantial. In the US, the total estimated medical costs related to lung cancer were $\$ 12.1$ billion in 2010 and were expected to increase to $\$ 15.2$ billion by 2020 . $^{6}$

A primary factor that affects the prognosis for lung cancer patients is the stage at which the cancer is diagnosed. Diagnosis stage is partially dependent on delays in the patient presenting to the physician with symptoms and also on delays in a physician providing a definitive diagnosis both in general practice and in specialty practice. ${ }^{7}$ There are a number of studies that have attempted to understand the delays associated with the diagnosis of lung cancer. ${ }^{7-11}$ Potential for delay is possible in four distinct phases prior to a definitive diagnosis of lung cancer: 1) between the first malignant change and the first symptom, 2) between the first symptom and presentation, 3) between the first presentation and diagnosis, and 4) between diagnosis and staging/ treatment. ${ }^{11}$ The slow-growing characteristics of some lung cancers, particularly adenocarcinomas, can lead to further delays in the diagnosis of lung cancer. ${ }^{12}$

Three recent studies linking cancer registries to Medicare data have demonstrated variations in guideline-concordant lung cancer care, time to diagnosis, time to treatment, and impact on prognosis, particularly among elderly, rural, and underserved populations. ${ }^{13-15}$ However, there still remains a need for a better understanding of costs incurred to diagnose NSCLC compared with costs associated with treating the disease and the delay time between suspicion of a lungrelated ailment and confirmed diagnosis of lung cancer. The objectives of this study were to assess the wait time to diagnose NSCLC and the health care utilization and the costs of diagnosing and treating the disease based on the stage of diagnosis.

\section{Patients and methods}

\section{Data source}

Data for this retrospective cohort study were obtained from the Optum Research Database (ORD), an administrative database of medical and pharmacy claims from a large US health insurance company, and were linked to data from a clinical cancer registry. The claims database includes $>13$ million commercial health plan enrollees annually with both medical and pharmacy benefits. Membership in the health plans is geographically diverse, with a concentration in the South and Midwest. The medical and pharmacy claims within the ORD include the International Classification of Diseases, Ninth Revision, Clinical Modification (ICD-9-CM) diagnosis and procedure codes, the Current Procedural Terminology (CPT) codes, enrollment information, site of service codes, the National Drug Codes (NDC), patient demographic information (age, gender, and state of residence), the type of insurance (PPO, HMO, and POS), paid amounts, and other information. The cancer registry, the Optum Oncology Management (OM) database, ${ }^{16}$ is affiliated with the health plan and includes information on the stage and date of diagnosis, histology, and other select clinical characteristics for a subset of commercial insurance enrollees in the ORD who were treated for lung cancer. Clinical information in this database was obtained through fax from the treating physician with telephone follow-up for incomplete submissions. The percentage of NSCLC (compared to SCLC) patients in the OM database is $\sim 80 \%$, and approximately half of NSCLC patients were diagnosed with Stage IV disease, which is similar to reported estimates. ${ }^{1}$ Information on date of death was linked from the Social Security Administration death master file.

No identifiable protected health information was extracted or accessed during the course of the study. Pursuant to the Health Insurance Portability and Accountability Act, ${ }^{17}$ the use of deidentified data for this study does not require institutional review board approval including waiver of patient's authorization.

\section{Patient selection}

Commercially insured adult patients (aged $\geq 18$ years at diagnosis) who were diagnosed with lung cancer between January 01, 2007, and September 30, 2011, and had both medical and pharmacy benefits during the study period were eligible for inclusion. The date of diagnosis obtained from the treating physician (as captured in the OM database) was considered as 
the index date. Patients were required to have 1 year of continuous enrollment in the health plan prior to diagnosis date (the baseline period) and $\geq 3$ months after the index date (follow-up). The time following the index date was used to assess outcomes including diagnosis and treatment patterns, survival, health care utilization, and costs. Patients with $<3$ months of follow-up due to death were included. Patients were excluded if there were no data available for the stage of lung cancer at diagnosis or the lung cancer type, if they had evidence of other primary cancers, or if they had $<3$ months of data available and had not died.

\section{Measurement}

Select patient characteristics were collected for the cohort at the index date, which included age (mean), gender (\%), comorbidity, cancer type (NSCLC vs SCLC) (\%), stage of NSCLC (\%), mean follow-up (by cohort), and those who died during the study period (by cohort). The primary outcomes of interest were use of diagnostic tests (biopsy, imaging, or laboratory/pathology test) prior to diagnosis (index date), the type of biopsy (if applicable), time to diagnosis (mean time from initial diagnostic test to index date), and rates of health care visits (office, outpatient, emergency room, and inpatient visits) by cancer stage (pre- and postdiagnosis). The rates of health care visits were calculated as the total number of events divided by the total follow-up time and per-patient per-month (PPPM) lung cancer-related health care costs during baseline and follow-up (by cancer stage). Total per-member per-month health care costs were calculated and presented separately for medical (for each category of service utilization) and pharmacy costs.

\section{Statistical analysis}

All study variables were stratified by stage at diagnosis and analyzed descriptively. Comparisons of baseline characteristics and outcome measures were evaluated by analysis of variance (ANOVA) $F$-test (for continuous variables) and chi-square test (for proportions). Kaplan-Meier analyses of mortality by stage at diagnosis were calculated as the time to death in years from the index date. Generalized linear multivariate models were conducted to explore the differences in total follow-up costs based on surgery type (open vs minimally invasive), stage at diagnosis, age, gender, baseline comorbidity, and presence of chronic obstructive pulmonary disease.

\section{Results}

\section{Study cohorts and patient characteristics}

Figure 1 presents the study sample selection. Between January 01, 2007, and September 30, 2011, 5,128 patients diag- nosed with lung cancer were identified from the OM database. There were 3,423 patients who met continuous enrollment criteria, and 3,149 had complete information on lung cancer type and stage at diagnosis. Among these, 1,507 patients had both medical and pharmacy benefits during the study period and $80 \%(n=1,210)$ were NSCLC patients.

Baseline characteristics for the NSCLC study population and comparisons between the stages of NSCLC are presented in Table 1. Most patients were diagnosed with Stage IV disease (Stage I=179 [15\%], Stage II=130 [11\%], Stage IIIa $=65$ [5\%], Stage IIIb=279 [23\%], and Stage IV=557 [46\%]). Approximately 56\% were males, and the mean age of all patients was 59 years and not significantly different by stage at diagnosis. The highest percentage of death during the study period was among the Stage IV patient cohort (Table 1) who had the lowest median survival (Figure 2; $P<0.001$ ), which contributed to Stage IV patients having the shortest follow-up time (Table 1).

\section{Primary outcomes}

Diagnostic testing in the 12 months prior to the date of diagnosis (but not including the date of diagnosis) is provided in Table 2. Most (93.6\%) patients had evidence of diagnostic tests (biopsy, imaging, or laboratory/pathology test) beginning 5 to 6 months prior to diagnosis. Bronchoscopic biopsy was the most common biopsy type (33\% of all NSCLC patients). Use of bronchoscopic biopsy with navigational bronchoscopy or with ultrasound was relatively low during both the baseline ( $<3 \%$ and $<10 \%$, respectively) and follow-up ( $<3 \%$ and $<18 \%$, respectively) periods. There was, however, an increasing trend for bronchoscopic biopsy with navigational bronchoscopy ( $0 \%$ in 2007 to $2 \%$ in 2011) and with ultrasound ( $2 \%$ in 2007 to $16 \%$ in 2011) over time in the follow-up period (not shown in table). In total, 572 patients received 668 biopsies and 1,127 patients received 3,319 imaging tests.

The rates of health care utilization before and after diagnosis are provided in Table 3 . The rates of health care utilization prior to diagnosis were similar, despite the stage of cancer at diagnosis. However, compared with patients diagnosed with later stage disease, those diagnosed with earlier stages of disease had lower rates of health care utilization after diagnosis over the study period.

The PPPM total health care, medical, and pharmacy costs prior to and after diagnosis are presented in Table 3. The mean PPPM total health care costs pre- and postdiagnosis were $\$ 2,407$ (standard deviation $[\mathrm{SD}]=\$ 3,364$ ) and $\$ 16,577$ $(\mathrm{SD}=\$ 33,550)$, respectively. The mean PPPM costs across 


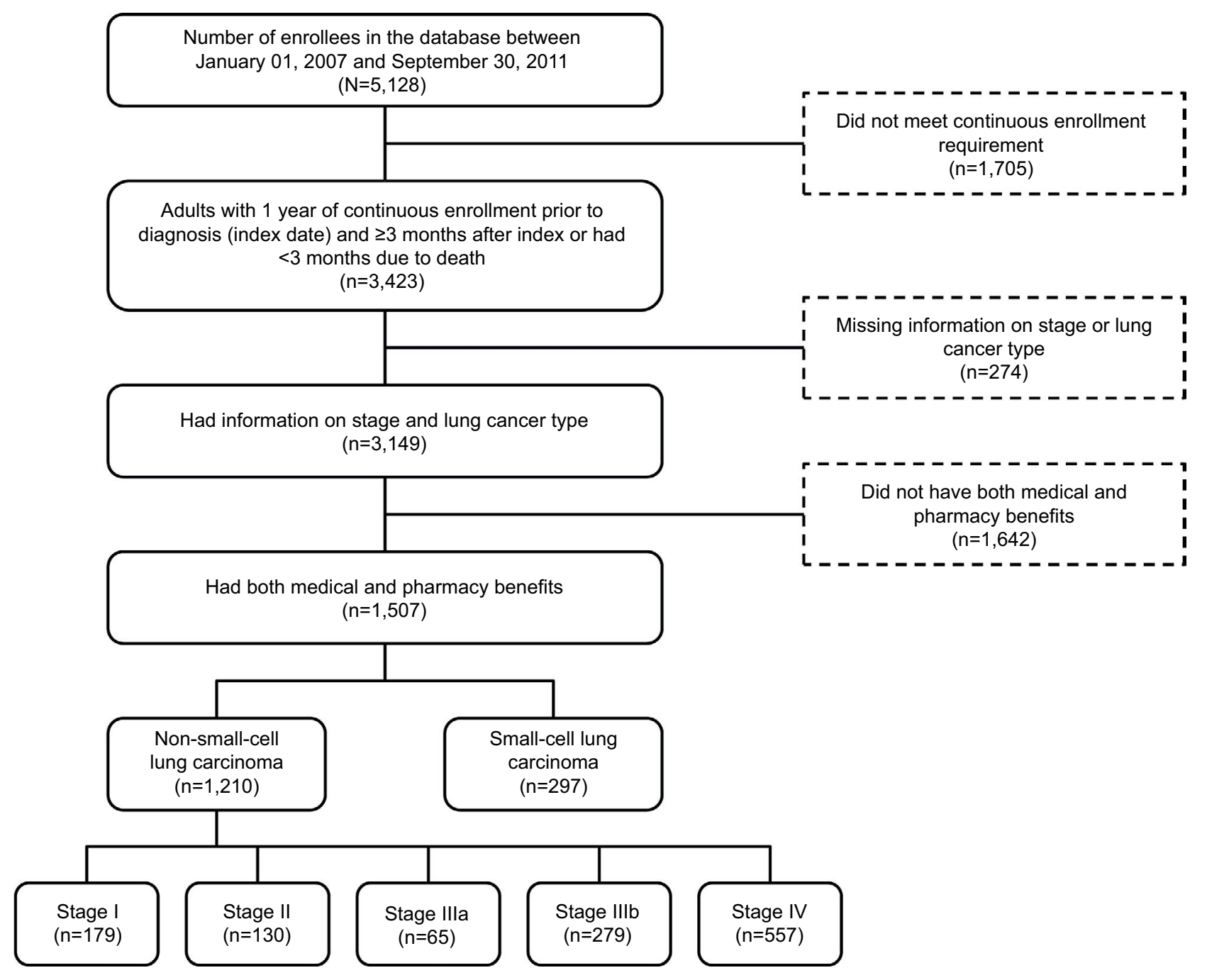

Figure I Patient selection and inclusion.

all cost categories during the 12-month baseline period were not significantly different by cohort (total health care costs, $P=0.666$; medical costs, $P=0.736$; and pharmacy costs, $P=0.415$ ). PPPM total health care costs after lung cancer diagnosis were highest among patients diagnosed with Stage IV disease (mean $=\$ 21,441, \mathrm{SD}=\$ 29,777$ ) and lowest among patients diagnosed with Stage I disease (mean $=\$ 7,239$, $\mathrm{SD}=\$ 7,611)$. The mean PPPM costs after diagnosis were significantly different across cancer stage cohorts (total health care costs, $P<0.001$; medical costs, $P<0.001$; and pharmacy costs, $P<0.001$ ). Figure 3 presents a graphical representation of PPPM costs pre- and postdiagnosis. A multivariate regression analysis found that only stage of diagnosis was a significant independent predictor of total health care cost $(P<0.001$ for Stage I vs Stage II, IIIa, IIIb, or IV).

\section{Discussion}

From among the denominator population of younger, commercially insured enrollees, the characteristics of the study sample of lung cancer patients were similar to what have been observed in previous studies. In this study, NSCLC was the most common histological type of cancer ( $80 \%$ ), which is consistent with what is found nationally in the US. ${ }^{5,18}$ Most NSCLC patients in this study were diagnosed in the later stages of the disease (Stage IIIb=23\% and Stage IV=46\%), which is similar to what has been found in previous studies. ${ }^{1,5,8}$

This study revealed that most patients have diagnostic testing initiated at an average of 5 to 6 months prior to a definitive lung cancer diagnosis by the physician. Other studies have identified delays in the diagnosis of lung cancer, and these issues are not unique to US lung cancer patients. ${ }^{7,9,13,19,20} \mathrm{In}$ a 2016 study of a West Virginia Cancer Registry, Nadpara et $\mathrm{al}^{13}$ reported a median symptom-to-diagnosis delay of $>6$ months. Salomaa et $\mathrm{al}^{7}$ assessed the delays in diagnosis and treatment of lung cancer from the patient's first experience with symptoms to general practitioner and specialist visits, through diagnosis and treatment from retrospective records from the Turku University Hospital in Finland. The median 
Table I Characteristics of all NSCLC patients at baseline and by cancer stage

\begin{tabular}{|c|c|c|c|c|c|c|c|}
\hline Characteristics & $\begin{array}{l}\text { All NSCLC } \\
(n=1,2 \mid 0), \\
\text { mean (SD) }\end{array}$ & $\begin{array}{l}\text { Stage I } \\
(\mathrm{n}=179), \\
\text { mean (SD) }\end{array}$ & $\begin{array}{l}\text { Stage II } \\
(n=130), \\
\text { mean (SD) } \\
\end{array}$ & $\begin{array}{l}\text { Stage IIla } \\
(n=65), \\
\text { mean (SD) }\end{array}$ & $\begin{array}{l}\text { Stage IIlb } \\
(n=279), \\
\text { mean (SD) }\end{array}$ & $\begin{array}{l}\text { Stage IV } \\
(n=557), \\
\text { mean (SD) }\end{array}$ & $P$-value \\
\hline Age (years) & $59(8)$ & $60(7)$ & $59(8)$ & $58(\mathrm{II})$ & $59(8)$ & $59(9)$ & 0.803 \\
\hline Follow-up (years) & I.I (0.9) & $1.5(1.0)$ & $1.4(1.0)$ & $1.8(1.2)$ & I.I (0.9) & $0.9(0.8)$ & $<0.001$ \\
\hline Baseline Charlson & $3.6(2.8)$ & $2.9(1.9)$ & $3.2(2.2)$ & $3.3(2.6)$ & $3.4(2.7)$ & $4.0(3.1)$ & $<0.001$ \\
\hline \multicolumn{8}{|l|}{ comorbidity index } \\
\hline \multicolumn{8}{|l|}{ Age categories (years) } \\
\hline $18-34$ & $5(<1)$ & $0(0)$ & $0(0)$ & $2(3)$ & $0(0)$ & $3(<1)$ & 0.008 \\
\hline $35-44$ & $35(3)$ & $3(2)$ & $4(3)$ & $3(5)$ & $10(4)$ & $15(3)$ & 0.699 \\
\hline $45-54$ & $293(24)$ & $38(21)$ & $31(24)$ & $19(29)$ & $68(24)$ & $137(25)$ & 0.769 \\
\hline $55-64$ & $626(52)$ & $106(59)$ & $67(52)$ & $22(34)$ & $142(5 \mid)$ & $289(52)$ & 0.014 \\
\hline $65-74$ & $200(17)$ & $29(16)$ & $23(18)$ & $16(25)$ & $46(16)$ & $86(15)$ & 0.448 \\
\hline$\geq 75$ & $5 I(4)$ & $3(2)$ & $5(4)$ & $3(5)$ & $13(5)$ & $27(5)$ & 0.460 \\
\hline \multicolumn{8}{|l|}{ Gender } \\
\hline Male & $682(56)$ & $79(44)$ & $79(61)$ & $37(57)$ & $157(56)$ & $330(59)$ & 0.008 \\
\hline Female & $528(44)$ & $100(56)$ & $51(39)$ & $28(43)$ & $122(44)$ & $227(4 I)$ & 0.008 \\
\hline \multicolumn{8}{|l|}{ Geographic region } \\
\hline Northeast & $127(\mathrm{II})$ & $20(\mathrm{II})$ & $14(11)$ & $5(8)$ & $31(11)$ & $57(10)$ & 0.939 \\
\hline Midwest & $336(28)$ & $51(28)$ & $27(21)$ & $12(18)$ & $81(29)$ & $165(30)$ & 0.125 \\
\hline South & $628(52)$ & $86(48)$ & $80(62)$ & $41(63)$ & $147(53)$ & $274(49)$ & 0.028 \\
\hline West & $119(10)$ & $22(12)$ & $9(7)$ & $7(11)$ & $20(7)$ & $61(11)$ & 0.236 \\
\hline Death during study period & 467 (39) & $20(11)$ & $22(17)$ & $18(28)$ & $107(38)$ & $300(54)$ & $<0.001$ \\
\hline
\end{tabular}

Abbreviations: NSCLC, non-small-cell lung cancer; SD, standard deviation.
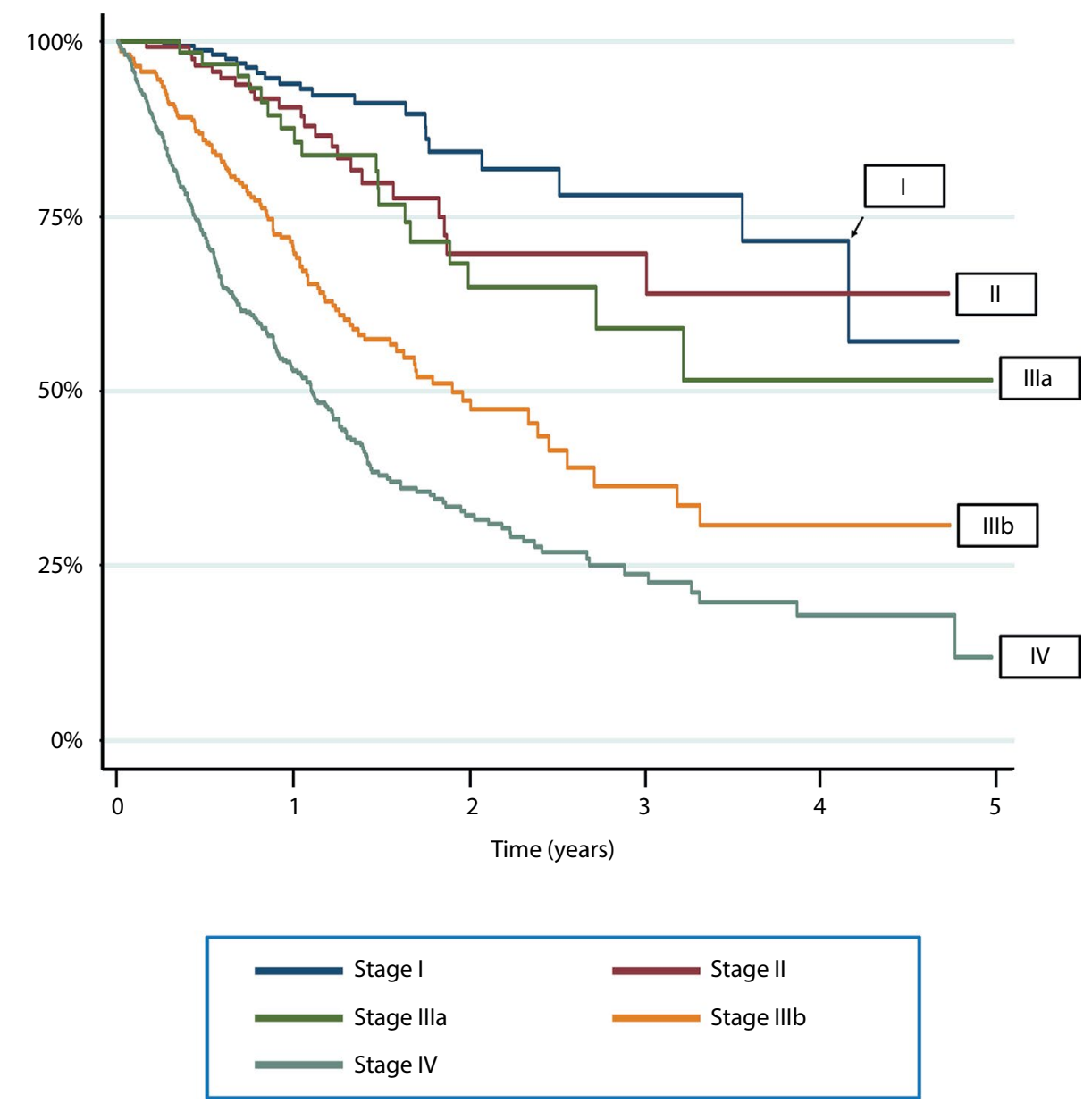

Figure 2 Kaplan-Meier survival curves of mortality by stage of disease. 
Table 2 Summary of diagnostic testing in 12 months prior to the date of diagnosis

\begin{tabular}{|c|c|c|c|c|c|c|}
\hline Diagnostic testing & $\begin{array}{l}\text { All NSCLC } \\
(n=1,210)\end{array}$ & $\begin{array}{l}\text { Stage I } \\
(n=179)\end{array}$ & $\begin{array}{l}\text { Stage II } \\
(n=130)\end{array}$ & $\begin{array}{l}\text { Stage IIla } \\
(n=65)\end{array}$ & $\begin{array}{l}\text { Stage IIlb } \\
(n=279)\end{array}$ & $\begin{array}{l}\text { Stage IV } \\
(n=557)\end{array}$ \\
\hline \multicolumn{7}{|l|}{ Use of diagnostic tests, $\mathrm{n}(\%)$} \\
\hline Imaging & I,I 27 (93) & $166(93)$ & $124(95)$ & $65(100)$ & $258(92)$ & $514(92)$ \\
\hline$C T^{*}$ & $911(75)$ & $143(80)$ & $102(78)$ & $58(89)$ & $212(76)$ & $396(7 I)$ \\
\hline $\mathrm{PET}^{*}$ & $487(40)$ & $109(6 \mathrm{I})$ & $76(58)$ & $32(49)$ & $109(39)$ & $161(29)$ \\
\hline MRI & II (I) & $2(1)$ & $I(I)$ & $\mathrm{I}(2)$ & $3(1)$ & $4(1)$ \\
\hline X-ray* & $\mathrm{I}, 084(90)$ & $165(92)$ & $124(95)$ & $64(98)$ & $25 I(90)$ & $480(86)$ \\
\hline Other (chest/lung) & $38(3)$ & $3(2)$ & $3(2)$ & $4(6)$ & $10(4)$ & $18(3)$ \\
\hline Other & $788(65)$ & $118(66)$ & $79(61)$ & $43(66)$ & $177(63)$ & $371(67)$ \\
\hline Total imaging tests received & 3,319 & 540 & 385 & 202 & 762 & 1,430 \\
\hline Laboratory/pathology*,a & $770(64)$ & $120(67)$ & $91(70)$ & $49(75)$ & $175(63)$ & $335(60)$ \\
\hline Biopsy & $572(47)$ & $81(45)$ & 77 (59) & $37(57)$ & $149(53)$ & $228(4 I)$ \\
\hline Bronchoscopic & $404(33)$ & $45(25)$ & $58(45)$ & $30(46)$ & $105(38)$ & $166(30)$ \\
\hline With navigational bronchoscopy & $6(1)$ & $0(0)$ & I (2) & $0(0)$ & $3(3)$ & $2(1)$ \\
\hline With ultrasound $d^{*, b}$ & $28(7)$ & $\mathrm{I}(2)$ & $5(9)$ & $2(7)$ & $10(10)$ & $10(6)$ \\
\hline Percutaneous* & $245(20)$ & $50(28)$ & $33(25)$ & $15(23)$ & $58(2 I)$ & $89(16)$ \\
\hline Open surgery & $19(2)$ & $3(2)$ & $2(2)$ & $3(5)$ & $7(3)$ & $4(1)$ \\
\hline Total biopsies received & 668 & 98 & 93 & 48 & 170 & 259 \\
\hline $\begin{array}{l}\text { Time from initial prediagnostic test to diagnosis (months), } \\
\text { mean (SD) }\end{array}$ & $5.4(4.2)$ & $6.2(4.1)$ & $5.7(4.2)$ & $6.2(4.1)$ & $5.2(4.2)$ & $5.0(4.2)$ \\
\hline
\end{tabular}

Notes: ${ }^{*} p<0.05$ across stage cohorts. alncluding cytopathology, molecular cytogenetics, surgical pathology, gross, and microscopic examination. ${ }^{b}$ Subset of bronchoscopic biopsy, includes linear or radial endobronchial ultrasound.

Abbreviations: NSCLC, non-small-cell lung cancer; CT, computed tomography; MRI, magnetic resonance imaging; PET, positron emission tomography; SD, standard deviation.

Table 3 Health care utilization rates and per-member per-month costs in the NSCLC cohort pre- and postdiagnosis

\begin{tabular}{|c|c|c|c|c|c|c|}
\hline Health care utilization & $\begin{array}{l}\text { All NSCLC } \\
(n=1,2 \mid 0)\end{array}$ & $\begin{array}{l}\text { Stage I } \\
(n=\mid 79)\end{array}$ & $\begin{array}{l}\text { Stage II } \\
(n=130)\end{array}$ & $\begin{array}{l}\text { Stage IIla } \\
(n=65)\end{array}$ & $\begin{array}{l}\text { Stage IIIb } \\
(n=279)\end{array}$ & $\begin{array}{l}\text { Stage IV } \\
(n=557)\end{array}$ \\
\hline \multicolumn{7}{|l|}{ Prior to diagnosis } \\
\hline Office visits & 14.5 & 16.7 & 15.9 & 16.9 & 13.9 & 13.6 \\
\hline Outpatient visits & 9.3 & 11.4 & 9.4 & 10.5 & 9.3 & 8.6 \\
\hline Emergency room visits & 1.0 & 0.9 & 0.8 & 0.8 & 0.8 & I.I \\
\hline Hospitalizations & 0.5 & 0.6 & 0.6 & 0.6 & 0.4 & 0.5 \\
\hline Total health care costs (USD) & $\$ 2,407(3,364)$ & $\$ 2,667(3,421)$ & $\$ 2,456(2,790)$ & $\$ 2,12$ I $(2,359)$ & $\$ 2,503(4,016)$ & $\$ 2,298(3,209)$ \\
\hline Medical costs & $\$ 2,202(3,252)$ & $\$ 2,429(3,370)$ & $\$ 2,209(2,629)$ & $\$ 1,939(2,207)$ & $\$ 2,299(3,924)$ & $\$ 2,109(3,074)$ \\
\hline Physician office/clinic & $\$ 343(1,014)$ & $\$ 342(550)$ & $\$ 337(53 \mathrm{I})$ & $\$ 385(595)$ & $\$ 372(1,487)$ & $\$ 325(962)$ \\
\hline Inpatient & $\$ 1,110(2,432)$ & $\$ 1,167(2,266)$ & $\$ 1,124(2,165)$ & $\$ 879(1,7 \mid 3)$ & $\$ 1,207(3,228)$ & $\$ 1,066(2,138)$ \\
\hline Emergency room & $\$ 18$ & $\$ 17(31)$ & $\$ 15(28)$ & $\$ 22(37)$ & $\$ 16(31)$ & $\$ 19(39)$ \\
\hline Hospital outpatient & $\$ 664(1,393)$ & $\$ 788(1,376)$ & $\$ 670(950)$ & $\$ 602(802)$ & $\$ 638(854)$ & $\$ 644(1,720)$ \\
\hline Other & $\$ 67$ (349) & $\$ 114(717)$ & $\$ 64(196)$ & $\$ 51(116)$ & $\$ 65(206)$ & $\$ 55(259)$ \\
\hline Pharmacy costs & $\$ 206(393)$ & $\$ 238(333)$ & $\$ 247(495)$ & $\$ 182(306)$ & $\$ 204(420)$ & $\$ 189(379)$ \\
\hline \multicolumn{7}{|l|}{ After diagnosis } \\
\hline Office visits & 43.4 & 29.7 & 39.1 & 43.7 & 48.6 & 48.8 \\
\hline Outpatient visits & 28.6 & 18.2 & 19.3 & 24.0 & 35.4 & 33.9 \\
\hline Emergency room visits & 1.6 & 1.1 & 1.2 & 1.3 & 1.9 & 1.9 \\
\hline Hospitalizations & 1.6 & 1.0 & 1.1 & 1.3 & 1.6 & 2.0 \\
\hline \multirow[t]{2}{*}{ Total health care costs (USD)* } & $\$ 16,577(33,550)$ & $\$ 7,239(7,611)$ & $\$ 9,484(8,520)$ & $\$ 11,193(8,826)$ & $\$ 17,415(53,839)$ & $\$ 21,441$ \\
\hline & & & & & & $(29,777)$ \\
\hline \multirow[t]{2}{*}{ Medical costs* } & $\$ 15,856(33,517)$ & $\$ 6,888(7,499)$ & $\$ 9,100(8,433)$ & $\$ 10,542(8,729)$ & $\$ 16,743(53,840)$ & $\$ 20,490$ \\
\hline & & & & & & $(29,804)$ \\
\hline Physician office/clinic* & $\$ 3,566(4,5 \mid 3)$ & $\$ 1,343(2,733)$ & $\$ 2,22$ I $(2,146)$ & $\$ 3,345(3,856)$ & $\$ 3,46 \mathrm{I}(4,546)$ & $\$ 4,673(5,053)$ \\
\hline Inpatient & $\$ 7,102(3 I, 24 I)$ & $\$ 3,449(5,383)$ & $\$ 3,83$ I $(5,292)$ & $\$ 3,455(4,790)$ & $\$ 7,740(52,049)$ & $\$ 9,145(27,139)$ \\
\hline Emergency room & $\$ 79(388)$ & $\$ 30(57)$ & $\$ 37(83)$ & $\$ 46(72)$ & $\$ 69(161)$ & $\$ 113(555)$ \\
\hline Hospital outpatient* & $\$ 4,644(6,842)$ & $\$ 1,877(3,207)$ & $\$ 2,697(4,236)$ & $\$ 3,345(4,171)$ & $\$ 5,106(5,626)$ & $\$ 5,907(8,44 I)$ \\
\hline Other & $\$ 466(2,445)$ & $\$ 188(467)$ & $\$ 315(1,299)$ & $\$ 35 I(I, 32 I)$ & $\$ 367(983)$ & $\$ 653(3,432)$ \\
\hline Pharmacy costs* & $\$ 72 I(I, 07 I)$ & $\$ 351(486)$ & $\$ 384(558)$ & $\$ 65 I(8 I I)$ & $\$ 672(94 I)$ & $\$ 951(1,305)$ \\
\hline
\end{tabular}

Notes: Data are expressed as \% or USD mean (standard deviation). $* P<0.05$ across stage cohorts.

Abbreviations: NSCLC, non-small-cell lung cancer; ER, emergency room. 


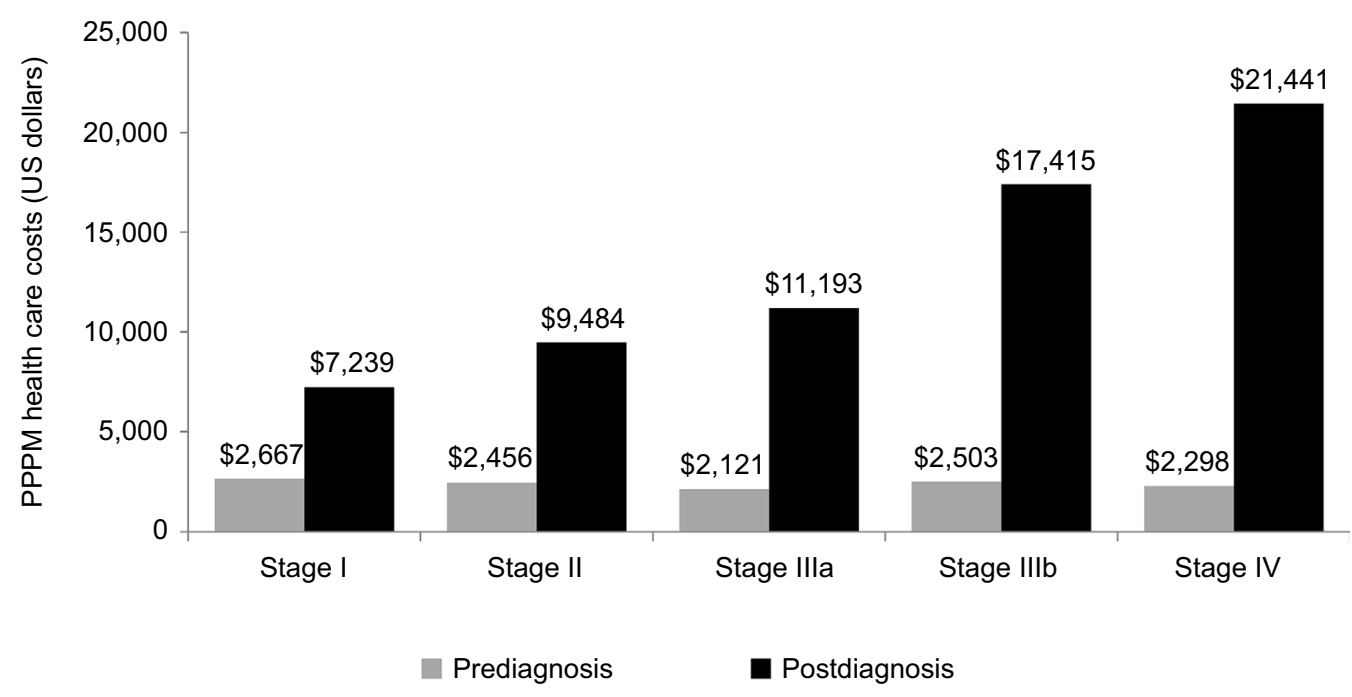

Figure 3 Comparison of per-patient per-month (PPPM) total health care costs pre- and postdiagnosis for non-small-cell lung carcinoma patients.

delay from the first symptoms to diagnosis was 98 days, between the first general practitioner visit and diagnosis was 52 days, and specialist visit to diagnosis was 15 days. A study from Canada reported a median total wait time from development of first symptoms to starting treatment of $\sim 4.5$ months, mentioning that patients visited up to four specialists before commencing treatment and had investigations ordered by multiple physicians. ${ }^{21}$ An earlier study from the UK noted that once a patient was referred to a respiratory specialist, the specialist spent a mean time of $\sim 2$ months investigating the patient before referring them on to a surgeon. ${ }^{9}$

Of note, it has been reported that the likelihood of receiving timely, guideline-appropriate care is significantly lower among patients diagnosed with early stage disease. ${ }^{13,15}$ In the current analysis, the time to diagnosis from the initial diagnostic test was 5 months for Stage IV patients versus 6.2 months for Stage I patients. Thus, there appears to be the potential to improve on the time to diagnosis across all stages.

The current study also demonstrated that health care utilization and costs were generally similar across cohorts in the 12 months prior to diagnosis, regardless of the stage of lung cancer at diagnosis. However, after lung cancer diagnosis, patients diagnosed with higher stage disease had greater health care utilization and incurred greater costs. Similar results were reported in an analysis of Surveillance, Epidemiology, and End Results (SEER)-Medicare data (1991-2003), finding that among NSCLC patients, the estimated cost of diagnosis and staging (without treatment) ranged from $\$ 10,000$ to $\$ 13,000$ while monthly treatment costs in the first 6 months after diagnosis ranged from $\$ 2,687$ (no treatment) to $\$ 9,257$ (chemotherapy and radiotherapy). Cost was lowest for NSCLC diagnosed at Stage I/II and highest for NSCLC diagnosed at Stage III. ${ }^{5}$ Similarly, in a UK study, mean 90-day costs were affected by treatment type (especially surgery), age, route of diagnosis, clinical stage, and cell type. ${ }^{22}$

\section{Limitations}

Although claims data are effective and efficient for examining treatment patterns and assessing health care utilization and costs, there are certain inherent limitations associated with claims data in general. Although stage and date of diagnosis were available from registry data, there are other clinical and disease-specific parameters that may influence choice and the timing of diagnostic testing. This limitation may cause a misinterpretation of the comparison of time from first diagnostic test to definitive diagnosis among the cohorts. Patients with lung cancer could be enrolled in clinical trials and some or all of the care received in this context may not generate insurance claims and therefore would not be included in this analysis, which would cause an underestimation of the total health care costs for these patients. Another limitation of this study is that there is no way of accurately determining when there was an initial suspicion of a lung ailment and, consequently, when that suspicion resulted in a physician further investigating the possibility of lung cancer. Health care utilization per patient was also only tracked over the study period and not over the remaining lifetime of each patient, which would not capture any ongoing or lung cancer recurrence costs in surviving patients. Finally, these data, although from a large and geographically diverse health plan, are from a single insurer and were restricted to commercially insured patients in the US and may not be representative of the uninsured, Medicare, Medicaid, other populations in the US, or populations outside the US. 


\section{Conclusion}

This current retrospective claims database analysis suggests that patients may experience long periods of delay between their first diagnostic test for lung cancer and a definitive diagnosis. As demonstrated in the current study, the costs associated with treating this disease are higher when the stage of lung cancer at diagnosis is more advanced. Diagnosis at earlier stages may reduce costs among patients with lung cancer. Future studies may examine the impact of interventions or diagnostic methods and assess whether these lead to a reduction of delays, which would contribute to an earlier stage of lung cancer at diagnosis.

\section{Acknowledgments}

This study was funded by Covidien (Covidien LP is an indirect wholly owned subsidiary of Medtronic plc.). The sponsor, Covidien, funded the study through a contract with Optum and provided input into the design and analysis in collaboration with the study authors. Andrew Beyer (Optum), John Hauschild (Covidien), and Kristin Hood (Covidien) provided editorial assistance for this manuscript. This research was presented at the CHEST 2015 Annual Meeting held in Montreal, Canada (October 25-28, 2015) as a poster with interim findings (Gildea et al. Chest. 2015;148[4]:588A).

\section{Author contributions}

Thomas R Gildea, David S Wilson, Curtis C Quinn, and D Kyle Hogarth participated in critical decisions regarding the study design, assisted with the interpretation of results, and critically reviewed the manuscript. Stacey DaCosta Byfield conceived the general study design, oversaw the statistical analyses, interpreted the results, and helped to draft the manuscript. All authors contributed toward data analysis, drafting and revising the paper and agree to be accountable for all aspects of the work.

\section{Disclosure}

Thomas R Gildea, D Kyle Hogarth, David S Wilson, and Curtis C Quinn either are or have been paid speakers for Covidien. Stacey DaCosta Byfield is an employee of Optum, which was contracted by Covidien to conduct the study. The authors report no other conflicts of interest in this work.

\section{References}

1. Siegel RL, Miller KD, Jemal A. Cancer statistics, 2017. CA Cancer J Clin. 2017;67(1):7-30.
2. Adebonojo SA, Bowser AN, Moritz DM, Corcoran PC. Impact of revised stage classification of lung cancer on survival: a military experience. Chest. 1999;115(6):1507-1513.

3. van Rens MT, de la Riviere AB, Elbers HR, van Den Bosch JM. Prognostic assessment of 2,361 patients who underwent pulmonary resection for non-small cell lung cancer, stage I, II, and IIIA. Chest. 2000; 117(2):374-379.

4. Howlader N, Noone AM, Krapcho M, et al., editors [webpage on the Internet]. SEER Cancer Statistics Review, 1975-2013. Bethesda, MD: National Cancer Institute; 2016. Available from: http://seer.cancer.gov/ csr/1975_2013/. Accessed April 2016.

5. Cipriano LE, Romanus D, Earle CC, et al. Lung cancer treatment costs, including patient responsibility, by disease stage and treatment modality, 1992 to 2003. Value Health. 2011;14(1):41-52.

6. Mariotto AB, Yabroff KR, Shao Y, Feuer EJ, Brown ML. Projections of the cost of cancer care in the United States: 2010-2020. J Natl Cancer Inst. 2011;103(2):117-128.

7. Salomaa ER, Sallinen S, Hiekkanen H, Liippo K. Delays in the diagnosis and treatment of lung cancer. Chest. 2005;128(4):2282-2288.

8. Koyi H, Hillerdal G, Branden E. Patient's and doctors' delays in the diagnosis of chest tumors. Lung Cancer. 2002;35(1):53-57.

9. Billing JS, Wells FC. Delays in the diagnosis and surgical treatment of lung cancer. Thorax. 1996;51(9):903-906.

10. Myrdal G, Lambe M, Hillerdal G, Lamberg K, Agustsson T, Stahle E. Effect of delays on prognosis in patients with non-small cell lung cancer. Thorax. 2004;59(1):45-49.

11. Moody A, Muers M, Forman D. Delays in managing lung cancer. Thorax. 2004;59(1):1-3.

12. Yoshimoto A, Tsuji H, Takazakura E, et al. Reasons for the delays in the definitive diagnosis of lung cancer for more than one year from the recognition of abnormal chest shadows. Intern Med. 2002;41(2):95-102.

13. Nadpara PA, Madhavan SS, Tworek C. Disparities in lung cancer care and outcomes among elderly in a medically underserved state population-a cancer registry-linked database study. Popul Health Manag. 2016;19(2):109-119.

14. Nadpara PA, Madhavan SS, Tworek C, Sambamoorthi U, Hendryx M, Almubarak M. Guideline-concordant lung cancer care and associated health outcomes among elderly patients in the United States. $J$ Geriatr Oncol. 2015;6(2):101-110.

15. Nadpara P, Madhavan SS, Tworek C. Guideline-concordant timely lung cancer care and prognosis among elderly patients in the United States: a population-based study. Cancer Epidemiol. 2015;39(6): 1136-1144.

16. Whyte JL, Engel-Nitz NM, Teitelbaum A, Gomez Rey G, Kallich JD. An evaluation of algorithms for identifying metastatic breast, lung, or colorectal cancer in administrative claims data. Med Care. 2015;53(7):e49-e57.

17. Health Insurance Portability and Accountability Act of 1996. Public Law 104-191, 104th Congress. 1996. Available from: https://www.gpo.gov/ fdsys/pkg/PLAW-104publ191/pdf/PLAW-104publ191.pdf. Accessed April 24, 2017.

18. Jemal A, Thun MJ, Ries LA, et al. Annual report to the nation on the status of cancer, 1975-2005, featuring trends in lung cancer, tobacco use, and tobacco control. J Natl Cancer Inst. 2008;100(23):1672-1694.

19. Cheung WY, Butler JR, Kliewer EV, et al. Analysis of wait times and costs during the peri-diagnostic period for non-small cell lung cancer. Lung Cancer. 2011;72(1):125-131.

20. Arca JA, Ramos MA, de la Infanta RG, Lopez CP, Perez LG, Lopez JL. Coste hospitalario del diagnóstico del cáncer de pulmón. [Lung cancer diagnosis: hospitalization costs]. Arch Bronconeumol. 2006; 42(11):569-574. Spanish.

21. Ellis PM, Vandermeer R. Delays in the diagnosis of lung cancer. JThorac Dis. 2011;3(3):183-188.

22. Kennedy MP, Hall PS, Callister ME. Factors affecting hospital costs in lung cancer patients in the United Kingdom. Lung Cancer. 2016;97:8-14. 
ClinicoEconomics and Outcomes Research is an international, peerreviewed open-access journal focusing on health technology assessment, pharmacoeconomics and outcomes research in the areas of diagnosis, medical devices, and clinical, surgical and pharmacological intervention. The economic impact of health policy and health systems organization also constitute important areas of coverage. The manuscript management system is completely online and includes a very quick and fair peer-review system, which is all easy to use. Visit http://www.dovepress.com/testimonials.php to read real quotes from published authors.

Submit your manuscript here: https://www.dovepress.com/clinicoeconomics-and-outcomes-research-journal 